\title{
Correction: Population Distribution Analyses Reveal a Hierarchy of Molecular Players Underlying Parallel Endocytic Pathways
}

Gagan D. Gupta, Gautam Dey, Swetha MG, Balaji Ramalingam, Khader Shameer, Joseph Jose Thottacherry, Joseph Mathew Kalappurakkal, Mark T. Howes, Ruma Chandran, Anupam Das, Sindhu Menon, Robert G. Parton, R. Sowdhamini, Mukund Thattai, Satyajit Mayor

In addition to the noted affiliation, Ruma Chandran is affiliated with: School of Life Sciences, Manipal Academy of Higher Education, Manipal, Karnataka, India.

\section{Reference}

1. Gupta GD, Dey G, MG S, Ramalingam B, Shameer K, Thottacherry JJ, et al. (2014) Population Distribution Analyses Reveal a Hierarchy of Molecular Players Underlying Parallel Endocytic Pathways. PLoS ONE 9(6): e100554. https://doi.org/10.1371/journal.pone.0100554 PMID: 24971745

f open access

Citation: Gupta GD, Dey G, MG S, Ramalingam B, Shameer K, Thottacherry JJ, et al. (2018) Correction: Population Distribution Analyses Reveal a Hierarchy of Molecular Players Underlying Parallel Endocytic Pathways. PLOS ONE 13(9): e0204770. https://doi.org/10.1371/journal. pone.0204770

Published: September 21, 2018

Copyright: ๑ 2018 Gupta et al. This is an open access article distributed under the terms of the Creative Commons Attribution License, which permits unrestricted use, distribution, and reproduction in any medium, provided the original author and source are credited. 